\title{
Identification and Antibiotic Resistance Patterns of Escherichia coli Isolated from Broilers Farms in Bahri Locality/Sudan
}

\author{
Hanadi Ali Elmofti ${ }^{1}$, Yassir A Almofti ${ }^{2}$, Nawal Noureldaim Abuelhassan ${ }^{3}$ and Nawal N Omer ${ }^{4 *}$ \\ ${ }^{1}$ Livestock and Rangelands department, Ministry of Agriculture and Animal Resources, River Nile State, Sudan \\ ${ }^{2}$ Department of Molecular Biology and Bioinformatics, College of Veterinary Medicine, University of Bahri, Khartoum, Sudan \\ ${ }^{3}$ Department of Animal Genetic Resources, Animal Resources Research Corporation (ARRC)-Animal production Research Khartoum North, \\ Khartoum, Sudan \\ ${ }^{4}$ Department of Animal Genetic Resources, Ministry of Animal Resources, Khartoum, Sudan \\ *Corresponding Author: Nawal N Omer, Department of Animal Genetic Resources, Ministry of Animal Resources, Khartoum, Sudan.
}

Received: October 14, 2019; Published: October 22, 2019

DOI: 10.31080/ASNH.2019.03.0512

\begin{abstract}
The aim of this study was to isolate and characterize Escherichia coli from broilers chickens in Bahri locality in Khartoum state and to elucidate their antimicrobial resistance profile. A total of 100 random cloacal and fecal samples were collected in the period of July to September 2018 from broilers farms in Bahri locality. The biochemical method identified 50 samples at $E$. coli. This 50 samples were further subjected to polymerase chain reaction (PCR) for the 16SrRNA gene that identified 20 isolates at E. coli. Concerning the antibiotic resistance profile, 16 isolates out of the 20 isolates demonstrated resistance to Erythromycin and Clarithromycin with resistance percentages of $80 \%$ for each. Also only 3 isolates demonstrated susceptibility to Azithromycin (15\%) while 17 isolates demonstrated resistance to Azithromycin (85\%). In general the isolates demonstrated resistance to macrolides with resistance percentage ranges between 80 to $85 \%$. In case of the Tetracycline, the isolates also showed resistance percentage of $80 \%$. The isolates showed moderate resistance to the Ciprofloxacin since 9 isolates showed susceptibility to the Ciprofloxacin (55\% resistance). It is noteworthy that according to the number of isolates the prevalence of $E$. coli in this study was found to be $20 \%$. Taken together, distinct from the other studies conducted in Khartoum State, this study used the molecular characterization method (PCR) for identification of the isolates as $E$. coli which is considered as an accurate and sensitive mean. Moreover the isolates exhibited antibiotic resistance patterns to the tested antibiotics which may raise the imprudent use of antibiotics in broilers industry.

Keywords: E. coli; Broiler Farms; Biochemical Identification; PCR; Antibiotic Resistance
\end{abstract}

\section{Introduction}

Poultry has been on earth for over 150 million years, dating back to the original wild jungle fowl. Ducks, geese, turkeys, pigeons, and chickens are on the list of the species under the general term poultry [1]. In Sudan, poultry products were commenced on a commercial basis in 1979 by Sudanese Kuwaiti poultry production Company. As a commodity, poultry products are highly demanded by the locals and the public of the neighboring countries especially Arabs [2].

Poultry meat is an important food product and constitutes a substantial portion of daily-consumed proteins. It is the second most widely eaten type of meat in the world, i.e. chicken, turkey, duck, geese, domesticated quail [3]. Poultry meat and eggs are pre- ferred rather than the other kinds of animal food products for a variety of reasons, dietary poultry meat is easy to prepare at homeand widely used in restaurants and fast - food establishment $[4,5]$.

Poultry keeping is an old practice, where the domestic fowl had been kept for generations in villages and backyards of dwellings to supply both eggs and meat for consumption. In the late seventies, with an increase in demand for poultry products, many investors from the Arab Gulf States started commercial egg and broiler production in Sudan. Ever since, the poultry industry significantly increased. This resulted in distribution of commercial poultry farming in Khartoum state and a round other big cities. With this growing industry, farmers in Sudan switched from open to the closed and semi-closed system [6]. The rapid expansion of poultry 
production in Sudan in recent years has stimulated many workers to study poultry major diseases that result in severe economic losses [7].

Colibacillosis has an important economic impact on poultry production worldwide. The majority of economic losses resulted from mortality and a decrease in productivity of the affected birds. It is a common disease in poultry flock especially in the intensive farming system [8]. Signs in birds affected with collibacillosis vary from sudden death to birds being off-color with their necks pulled into their bodies [9].

Several techniques for detection of $E$. coli spp. in fecal material are used such as cultures with selective media followed by a series of biochemical test. Identification of $E$. coli spp can also be performed by molecular methods such as PCR. This procedure is the most important development for research in molecular biology and it is fast, as well as highly sensitive and very specific [10]. The antibiotic resistance in poultry is now generally known to be due to the widespread use of antibiotics. This is considered as the main risk factor for the increase in the occurrence of antibiotic-resistant bacterial strains $[11,12]$. The aim of this study was to isolate and assess the antibiotic resistance profile of $E$. coli isolated from broilers farms in Bahri locality in Sudan.

\section{Material and Methods}

Collections of specimens

A total of 100 fecal and cloacal swabs were collected from close and semi-close poultry broilers farms. Sterile cotton swabs were inserted deeply in the cloaca and then rotated 3 to 5 times then pulled out gentle and placed in a sterile container. Fresh fecal samples were collected from the floor from different sites within the farm by a gloved hand. Each 10 fecal samples were placed in one sterile bag as one sample.

\section{Biochemical identification of the isolates}

For isolation and identification of Escherichia coli from the collected samples, the samples were first enriched by incubation for 12 hours at $37^{\circ} \mathrm{C}$, sub-culturing on nutrient agar plates to purify colonies followed by incubation at $37^{\circ} \mathrm{C}$ for another 24 hours. $\mathrm{Pu}$ rified isolates were further identified according to the reaction of Gram's stain, shape of the bacterial colonies, motility, colonial characteristics on selective media such as Eosine Methylene Blue agar media (EMB).The biochemical tests were performed according to the methods detailed in Cowan and Steel's Manual for the Identification of Medical Bacteria [13]. Tests performed included, Catalase-Oxidase tests, Indole test, Citrate utilization, Motility test, Kligler test, Voges- Proskauer reaction test (VP), Methyl red (MR) test and Indole test.

\section{Molecular characterization}

The molecular characterization of the isolates was also performed for the confirmation of the isolates as E. coli using Polymerase Chain Reaction (PCR). The target gene for the identification of the isolates was 16SrRNA gene.

\section{DNA extraction}

Samples that were retrieved from the conventional methods and suspected as E. coli spp were further analyzed by molecular methods using Polymerase Chain Reaction, PCR. The DNA was extracted from the sample according to the method described by [14].

\section{Primers}

The primers used for the PCR amplification were previously described by [15]. The forward primer was F-5GGGAGTAAAGTTAATACCTTTGCTC-3 and the reverse primer was R- 5-TTCCCGAAGGCACCAATC-3. The primers were donated by the laboratory of Molecular Biology and Bioinformatics at the University of Bahri.

\section{PCR amplification}

The components of the reaction mixture were optimized as follows: $2 \mu$ from extracted DNA as a template, $1 \mu \mathrm{l}$ from the forward, $1 \mu \mathrm{l}$ reverse primers. These components were added to ready master mix containing loading dye and the final volume was completed to $25 \mu \mathrm{l}$ with DW water. PCR reaction was performed in gene Amp PCR system (England) with a heated lid. The PCR reaction conditions were stated as previously described [15]. The PCR reaction conditions were as followed: $94^{\circ} \mathrm{C}$ for 5 minutes (initial denaturation) and $94^{\circ} \mathrm{C}$ for 2 minutes (denaturation). The annealing temperature was $56^{\circ} \mathrm{C}$ for 45 seconds. The extension was set to $72^{\circ} \mathrm{C}$ for 1 minute, followed by $72^{\circ} \mathrm{C}$ for 10 minutes as a final extension. The number of the PCR cycles was set to be 35 cycles.

\section{DNA gel electrophoresis}

DNA electrophoresis 50X stock solution was prepared as follows: $242 \mathrm{~g}$ tris, $37.2 \mathrm{~g} \mathrm{Na} 2$ EDTA, $800 \mathrm{ml}$ distilled water and was added and mixed thoroughly. A volume of $57.1 \mathrm{ml}$ of the acetic acid was added and the final volume was completed to one liter with deionized water. For the DNA electrophoresis running solution: $1 \mathrm{X}$ working solution: dilute the $50 \mathrm{X}$ to $1 \mathrm{X}$ by distilled water.

\section{Antibiotic sensitivity test}

Minimum inhibitory concentration (MIC) of the isolated strains was determined by using the broth microdilution method recommended by the clinical laboratory standards institute [16]. The antimicrobials tested consisted of the following macrolides: Erythromycin (ERY), Azithromycin (AZM) and Clarithromycin (CLA). The florouquilones Ciprofloxacin (CIP) and the Tetracycline (TET) were 
also tested. Resistant breakpoints were as following: ERY $\geq 32 \mu \mathrm{g} /$ $\mathrm{ml}, \mathrm{AZM} \geq 8 \mu \mathrm{g} / \mathrm{ml}, \mathrm{CLA} \geq 16 \mu \mathrm{g} / \mathrm{ml}, \mathrm{CIP} \geq 8 \mu \mathrm{g} / \mathrm{ml}$, and $\mathrm{TET} \geq 16 \mu \mathrm{g} / \mathrm{ml}$ [16].

\section{Results}

Biochemical examination

The summary of the results of all biochemical tests used in this study were summarized in table 1 and figure 1 . The thin smears were prepared from colonies collected from Mc Conky and $\mathrm{Nu}-$ trient agar for Gram's staining. As shown in figure 1 the staining revealed the isolates as Gram-negative, pink colored, small rod shaped appearance, arranged in single or paired under the microscopic examination. The motility test was performed using semisolid media (stabbing method). Figure 1 showed that the bacteria were obviously moved within the semisolid media. Moreover bacterial colonies in the EMB media with metallic shining characteristics may indicate the growth as E. coli. Figure 1 demonstrated that the bacteria colonies appeared as metallic shining colonies. Moreover citrate utilization test for was shown to be negative since no growth on the slant and no change in color to blue of the medium was observed. This indicated a negative result. Also the VP test provided that the isolates were positive for VP test as a pink color was observed at the top of the test. These results indicated the isolates as E. coli. The Kligler test was shown to be negative since no change in the color to dark blue was observed. This negative result further indicated the isolates as E. coli. Methyl red (MR) test provided red coloration was obtained. This result indicated the test was positive for methyl red. This result indicated the isolates as $E$. coli. The isolates were found to be indole positive since a faint red ring was obtained. All these examinations tentatively indicted the isolates E. coli.

\begin{tabular}{|l|l|}
\hline Characteristics & E. coli \\
\hline Gram's stain & -ve bacilli \\
\hline Motility & Motile \\
\hline Colony shape & Flat 2-3 mm \\
\hline Colonial Characteristics & $\begin{array}{l}\text { Flat } 2-3 \mathrm{~mm} \text {, metallic shining } \\
\text { in Eosin Methylin Blue, Lac- } \\
\text { tose fermenter in MacConkey }\end{array}$ \\
\hline Citrate utilization & -ve \\
\hline Voges-proskauer (vp) reaction & + ve \\
\hline Kliger test & ve- \\
\hline Methyl red test & ve+ \\
\hline Indol test & ve+ \\
\hline Growth in EMB media & Metallic shining \\
\hline
\end{tabular}

Table 1: biochemical characteristics used for identification of the isolates $E$. coli.

(+ ve) Positive (- ve) Negative

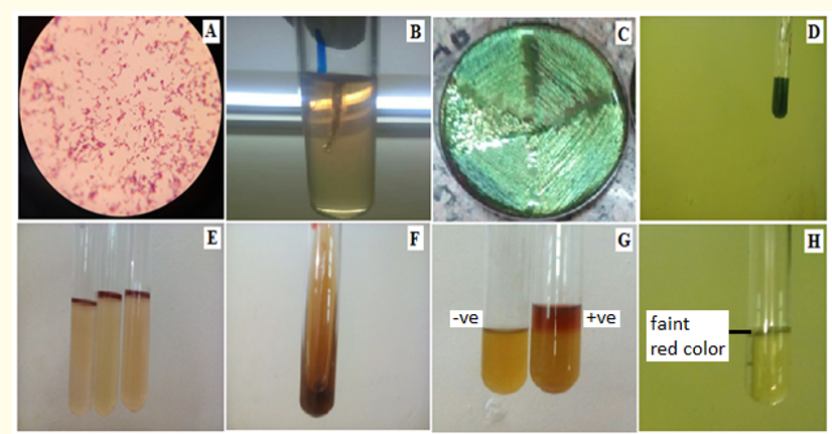

Figure 1: (A) Gram's stain, (B) Motility, (C) the growth of E. coli on agar media, (D) Citrate Utilization, (E) Voges- Proskauer,

(F) kilgler test, (G) Methyl red test and (H) Indole test.

\section{Molecular Characterization}

\section{DNA extraction}

As shown in figure 2 the quality of the DNA was checked in the gel electrophoresis. The Genomic DNA was shown as bands just passed out the wells of the gel after 30 minutes of run in the electrophoresis.

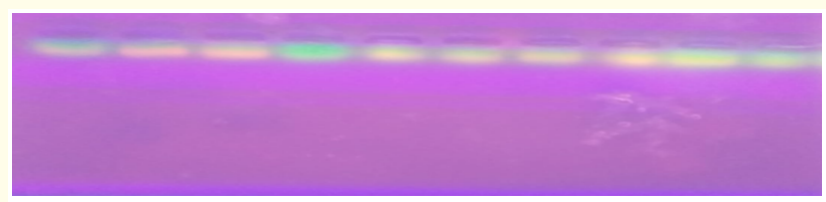

Figure 2: The DNA was extracted and the quality of the DNA was determined in the gel electrophoresis.

\section{PCR amplification}

The PCR was performed for the isolates that were obtained from the biochemical identification. Using the molecular identification method, 20 bacterial isolates were identified as E. coli. Figure 3 demonstrated a band size ( $584 \mathrm{bp}$ ) that indicated the isolates as E. coli.

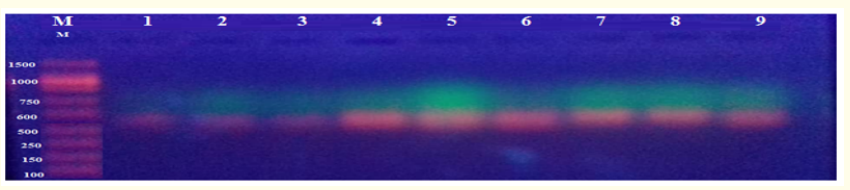

Figure 3: The PCR amplification of 16SrRNA gene of the suspected isolates of E.coli. The band size was expected to be $584 \mathrm{bp}$ that indicated isolates as E. coli. M was DNA ladder; lane 1, 2, 3, 4, $5,6,7,8$ and 9 were the amplicon of 16SrRNA gene that indicated isolates as E. coli spp. 


\section{Sensitivity to antibiotics}

Antibiotic sensitivity tested was performed according to CLSI, 2012. Table 2 demonstrated the sensitivity test of $E$. coli isolates against five antibiotics commonly used for the treatment of $E$. coli infection in human and broilers. For the macrolides, Erythromycin Clarithromycin and Azithromycin the resistant breakpoints were $\geq 32 \mu \mathrm{g} / \mathrm{ml} \geq 16 \mu \mathrm{g} / \mathrm{ml}$ and $\geq 8 \mu \mathrm{g} / \mathrm{ml}$, respectively. Out of the 20 tested isolates 16 isolates demonstrated resistance to each of Erythromycin and Clarithromycin (80\%). Only three isolates out of the 20 isolates demonstrated susceptibility to Azithromycin (15\%) while 17 isolates demonstrated resistance to Azithromycin (85\%). In general the isolates demonstrated resistance to macrolides with resistance percentage ranges between 80 to $85 \%$. In case of the Tetracycline the resistance breakpoint was $\geq 16 \mu \mathrm{g} / \mathrm{ml}$. The isolates also showed resistance to Tetracycline ( $80 \%)$. The isolates showed moderate resistance to the Ciprofloxacin. Out of the 20 isolates 9 isolates showed susceptibility to the Ciprofloxacin (55\% resistance).

As shown in figure 4 the average and the standard deviation (using the student $\mathrm{t}$ - test) of the sensitivity of the 20 isolates to each antibiotic was measure. The isolates showed least susceptibility to Erythromycin followed by Tetracycline, Clarithromycin. In case of the Azithromycin, beside the three susceptible isolates there were 8 isolates showed moderate resistance. Therefore the average of MIC for the 20 isolates showed low resistance. Isolates provided the best sensitivity to Ciprofloxacin as it scored the lowest MIC. Taken together the isolates showed resistance to Tetracycline and macrolides with exception of Azithromycin. In addition to that the isolates demonstrated the least resistance resistances to Ciprofloxacin.

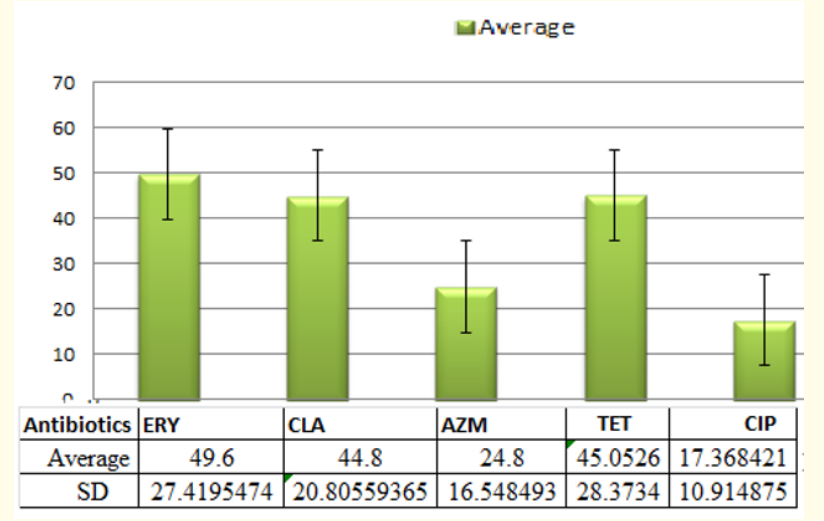

Figure 4: The average and the standard deviation (SD) of the twenty isolates MIC to each antibiotic used using the student $t$ test.

\section{Discussion}

Escherichia coli are one of the common microbial floras of gastrointestinal tract of poultry, human and other animals. This bacterium may become pathogenic to both poultry and human $[17,18]$.

\begin{tabular}{|c|c|c|c|c|c|}
\hline \multicolumn{7}{|c|}{ MIC ug/ml } \\
\hline Isolate & ERY & CLA & AZM & TET & CIP \\
\hline 1 & 16 & 32 & 16 & - & 16 \\
\hline 2 & 64 & 32 & 32 & 64 & 32 \\
\hline 3 & 64 & 64 & 16 & 32 & 8 \\
\hline 4 & 32 & 64 & 32 & 64 & 32 \\
\hline 5 & 64 & 32 & 16 & 16 & 8 \\
\hline 6 & 16 & 16 & 8 & 32 & 8 \\
\hline 7 & 32 & 16 & 16 & 32 & 8 \\
\hline 8 & 64 & 64 & 32 & 64 & 16 \\
\hline 9 & 64 & 64 & 32 & 64 & 16 \\
\hline 10 & 32 & 64 & 16 & 64 & 8 \\
\hline 11 & 64 & 64 & 16 & 128 & 32 \\
\hline 12 & 16 & 32 & 16 & 8 & 16 \\
\hline 13 & 64 & 64 & 32 & 32 & 8 \\
\hline 14 & 64 & 32 & 64 & 16 & 16 \\
\hline 15 & 64 & 64 & 16 & 16 & 8 \\
\hline 16 & 32 & 16 & 4 & 32 & 2 \\
\hline 17 & 16 & 32 & 4 & 64 & 32 \\
\hline 18 & 64 & 64 & 32 & 32 & - \\
\hline 19 & 128 & 64 & 32 & 64 & 32 \\
\hline 20 & 32 & 16 & 64 & 32 & 32 \\
\hline & & & & & \\
\hline
\end{tabular}

Table 2: The MIC of the twenty isolates of E.coli against different antimicrobial agents, the MIC was determined by the broth microdilution method according to CLSI, 2012. (ERY: Erythromycin; CLA: Clarithromycin; AZM: Azithromycin; TET: Tetracycline;

CIP: ciprofloxacin). Resistant breakpoints were as following: $\mathrm{ERY} \geq 32 \mu \mathrm{g} / \mathrm{ml}, \mathrm{AZM} \geq 8 \mu \mathrm{g} / \mathrm{ml}, \mathrm{CLA} \geq 16 \mu \mathrm{g} / \mathrm{ml}, \mathrm{CIP} \geq 8 \mu \mathrm{g} / \mathrm{ml}$, and TET $\geq 16 \mu \mathrm{g} / \mathrm{ml}$ (CLSI, 2012).(-): not assessed.

Although most isolates of $E$. coli are nonpathogenic but they are considered as indicator of faecal contamination in food and about 10 to $15 \%$ of intestinal coliforms are opportunistic and pathogenic serotypes [19] and cause a variety of lesions in immunocompromised hosts as well as in poultry. Among the diseases some are often severe and sometimes lethal infections such as meningitis, endocarditis, urinary tract infection, septicemia, epidemic diarrhea of adults and children [20]. Therefore it is of great importance to study $E$. coli in broilers and to assess the antimicrobial resistance profile of the isolates to the commonly used antibiotics. 
Generally the bacteriological conventional methods were commonly used for detection and identification of bacterial organisms as a preliminary identification of bacterial organisms. However the application of PCR for detection and identification of bacterial organisms has been described by several workers [21,22]. In this study 100 fecal and cloacal samples were collected from broilers farms in Bahri locality. The bacteriological identification methods identified 50 isolates as E. coli. However the described PCR assay in this study reproducibly and specifically detected only 20 isolates as E. coli from fecal and cloacal sample with specific 584 bp PCR products of the 16S rRNA gene. Therefore the sensitivity of the PCR was comparable or even more sensitive than the conventional bacteriological procedure for specific identification of organisms. According to this confirmed number of the isolates as E. coli the prevalence of E. coli in this study was found to be $20 \%$. This figure was nearly lower than the previous report of Mohamed-Noor., et al. [23] who reported a prevalence of $44 \%$. However the prevalence in this study was higher than that reported by Abdulahi., et al. [24] who reported a prevalence of $8.9 \%$ in closed system farms than open system $(3.2 \%)$ in broilers farms in Sudan.

Antibiotics are used in the poultry farms for multiple purposes such as growth promoters, prophylaxis and for therapeutic purposes $[23,25]$. These veterinary drugs include a large number of different types of compounds that can be administrated in the feed or in the drinking water. However the imprudent use of these drugs may exert adverse effects due to the presence of antibiotics residues and the presence of antibiotics resistant bacteria such as E. coli $[25,26]$. Moreover there are multiple scientific evidences that demonstrated the relationship between the use of antibiotics in food producing animals and the emergence and selection of antibiotics resistance bacteria $[23,25,26]$. Recent studies in Sudan and worldwide have reported antimicrobial residues and antibiotic resistant bacteria in food animal products such as chicken meat suggesting large-scale unregulated use of antibiotics by the poultry industry $[23,27,28]$. This is consistent with our observations as we also found a marked predominance of antibiotic resistance among E. coli isolates obtained from fecal and cloacal swaps in broilers chicken. Moreover E. coli isolates in different studies were tested for antimicrobial resistance of multiple antibiotics with different testing procedures. These isolates were grouped as susceptible, intermediate, resistant and multidrug resistant (multidrug resistance was defined as resistance to three or more classes of antibiotics $[29,30]$. In this study antimicrobial resistance was performed using broth microdilution method recommended by CLSI 2012 for Erythromycin, Clarithromycin, Azithromycin, Tetracycline and Cip- rofloxacin. In accordance to the antibiotics resistance breakpoints [16] our results coincided with previous studies since the isolated $E$ coli provided resistance to all tested antibiotics with exception to Ciprofloxacin that showed moderate resistance [23,27-31]. In addition to that our isolated E. coli demonstrated resistance to more the three antibiotics and thus showed multidrug resistance to the tested antibiotics. The isolates showed resistance to Tetracycline, Clarithromycin and Erythromycin with exception of Azithromycin. In addition to that, the isolates demonstrated the least resistance to Ciprofloxacin. For instance 16 isolates out of the 20 isolates demonstrated resistance to Erythromycin and Clarithromycin with resistance percentages of $80 \%$ for each. Also, only 3 isolates demonstrated susceptibility to Azithromycin (15\%) while 17 isolates demonstrated resistance to Azithromycin (85\%). In general the isolates demonstrated resistance to the tested macrolides with resistance percentage ranges between 80 to $85 \%$. In case of the Tetracycline, the isolates also showed resistance percentage of $80 \%$. The isolates showed moderate resistance to the Ciprofloxacin since 9 isolates showed susceptibility to the Ciprofloxacin (55\% resistance). This resistance in the $E$. coli isolates mainly attributed to the imprudent usage of the antibiotics in the broilers farms. Some studies demonstrated the resistance and virulence genes from avian pathogenic Escherichia coli (APEC) from broiler chickens $[31,32]$. Therefore further work is required to demonstrate these genes from avian pathogenic Escherichia coli (APEC) from broilerchickens in Sudan.

Taken together this study demonstrated that E. coli is a major contaminant in broilers farms and maybe responsible for disease conditions in broiler. Moreover E. coli isolates provided resistance to antibiotics used in this study and multi drug resistance (MDR).

\section{Conclusion}

This study confirmed the presence of susceptible and antibiotic resistant E. coli in Bahri locality in both semi close and closed system from poultry production farms. This study suggested that farms management practices play an important role in the level of the $E$. coli prevalence and may be the antibiotic resistance of the selected bacterial species with in differing poultry production farms. In this study twenty identified isolates were found resistant to at least one antibiotic which has raised some concerns about the efficacy of poultry antimicrobial therapy. The molecular method confirmed the results of traditional detection method of $E$. coli species with high specificity and sensitivity as potentially valuable tool of the detection method. 


\section{Acknowledgements}

Special thanks to University of Sudan Science and Technology, College of animal production for their support and guidance. My gratitude also extends to the technicians in the laboratories of the University of Bahri, College of Veterinary Medicine for their technical work assistance.

\section{Competing Interest}

The authors declared no competing interest.

\section{Bibliography}

1. Yang P., et al. "Ultra structural identification of telocytes in the muscularis of chicken ileum". Experimental and Therapeutic Medicine 10 (2015): 2325-2330.

2. Salih GE. Development communication and implementation of poultry farming technologies in the Gezira state. Ph. Dthesis. University of Gezira Sudan (2002).

3. Ralof and Janet HT. "Food for thought: Global food trends. Science News Online 31". Resistance of Campylobacter spp. And Salmonella Serovars in Organic Chickens from Maryland Retail Stores. Applied and Environmental Microbiology, 71, 4108-4111. Resistance to antibiotics: links between animals and humans". International Journal of Antimicrobial Agents 14 (2003): 327-335.

4. Mulder RW." Hygiene during transport, slaughter and processing". In: Richardson, R.I. and Mead, G.C., editors. Poultry Meat Science. Poultry Science Symposium" (1999).

5. Nahed M A. "Detection of salmonella species in chickens carcasses using genus specific primer belong to invA gene in Sohagcity , Egypt". Journal of Veterinary World (2016): 11251128.

6. Mohammed Elfatih. Economics of Poultry Production in Khartoum State, Sudan Msc Thesis. University of Khartoum (2009).

7. Elamin MM., et al. "Cooked sun-dried blood meal a potential source of lysine. 2. Effect on broiler performance Sudan". Journal of Animal Health and Production 3 (1990): 45-51.

8. Otaki Y. "Poultry disease control programme in Japan". Asian Livestock 20 (1995): 65-67.

9. Matin MA., et al. "Prevalence of colibacillosis in chickens in greater Mymensingh district of Bangladesh". Veterinary world 10 (2017): 29-33.

10. McPherson MJ., et al. "Polymerase Chain Reaction SCIENCE Life Sciences - Genetics and Genomics". Oxford: BIOS ; New York, NY: Springer (2000).
11. WHO/ FAO. "Risk assessments of salmonella in eggs and broiler chickens". World Health Organization and Food and Agriculture Organization of the United Nations, Geneva (2012).

12. Catry B., et al. "Antimicrobial resistance in livestock". Journal of Veterinary Pharmacology and Therapeutics 26 (2003): 81-93.

13. Barrow GI and Feltham RKA. "Cowan and steel's manual for the identification of medical bacteria". 3rd edition, Cambridge University Press (1993).

14. Wilfred Ruban S., et al. "Prevalence of food borne pathogens in market samples of chickens meat in Bangalore, India". International Food Research Journal 19 (2012): 1763-1765.

15. Tsen HY., et al. "Development and use of 16SrRNA gene targeted PCR primers for the identification of Escherichia coli cells in water". Journal of Applied Microbiology 85 (1998): 554-560.

16. CLSI. Performance standard for antimicrobial susceptibility testing, twenty second informational supplements 32 (2012).

17. Jawetz E., et al. "Review of Medical Microbiology". 16th ed. Los Altos, California: Long Medical Publication. (1984): 122-144.

18. Levine M. "Escherichia coli that cause diarrhea: enterotoxigenic, enteropathogenic, enteroinvasive, enterohemorrhagic and enteroadherent". The Journal of Infectious Diseases 155 (1987): 377-390.

19. Barnes HJ., et al. "Colibacillosis". Pages 131-139 in Diseases of Poultry. 10th ed. B. W. Calnek, ed. Mosby-Wolf Publication Ltd., London, UK (1997).

20. Daini OA., et al. "Quinolones Resistance and R-plasmids of some gram negative enteric Bacilli". African Journal of Clinical and Experimental Microbiology 6 (2005): 14-19.

21. Simmons K., et al. "Duplex PCR Methods for the Molecular Detection of Escherichia fergusonii Isolates from Broiler Chickens". Applied and Environmental Microbiology 80 (2014): 1941-1948.

22. Abdelrahman IO., et al. "PCR Detection of E. coli in Chicken Fecal Samples". International Journal of Molecular Medicine and Advance Sciences 4 (2008): 82-85.

23. Mohamed-Noor SE., et al. "Study of microbial contamination of broilers in modern abattoirs in Khartoum state". The Annals of the University Dunarea de Jos of Galati (2012).

24. Abdulahi S., et al. "Studies on avian colibacillosis in Bahri locality of Khartoum State, Sudan". World Journal of Pharmacy and Pharmaceutical Sciences 7 (2018): 43-55. 
25. Almofti Y A., et al. "Imprudent usage of antibiotics in dairy farms and antibiotics detection in milk". Scholars Research Library Annals of Biological Research 7 (2016): 36-42.

26. Singer RS., et al. "Potential impacts of antibiotic use in poultry production". Avian Diseases 50 (206): 161-172.

27. Eckburg PB., et al. "Microbiology: diversity of the human intestinal microbial flora". Science 308 (2005): 1635-1638.

28. Brower C H., et al. "The prevalence of extended-spectrum Beta-lactamase-producing multidrug-resistant Escherichia Coli in poultry chickens and variation according to farming practices in Punjab, India". Environmental Health Perspectives 125 (2017): 1-10.

29. Gregg S., et al. "Antibiotic-resistant Escherichia coli from retail poultry meat with different antibiotic use claims". BMC Microbiology 18 (2018): 174.

30. Sapkota AR., et al. "Lower prevalence of antibiotic-resistant Enterococci on U.S. conventional poultry farms that transitioned to organic practices". Environmental Health Perspectives 119 (2011): 1622-1628.

31. Amer MM., et al. "Antimicrobial resistance genes in pathogenic Escherichia coli isolated from diseased broiler chickens in Egypt and their relationship with the phenotypic resistance characteristics". Veterinary World 11 (2018): 1082-1088.

32. Manita Subedi., et al. "Antibiotic resistance pattern and virulence genes content in avian pathogenic Escherichia coli (APEC) from broiler chickens in Chitwan, Nepal". BMC Veterinary Research 14 (2018).

\section{Volume 3 Issue 11 November 2019}

(C) All rights are reserved by Nawal N Omer., et al. 